\title{
Beet Performance Under Different Irrigation Depths and Rock Powder Doses Added to Soil
}

\section{Diogo Luiz Fruet ${ }^{1 *}$, Muriel Tambani ${ }^{2}$, João Celio De Araujo ${ }^{3}$, Sidnei Leandro Sturmer ${ }^{4}$ and Romano Roberto Valicheski ${ }^{5}$}

${ }^{1}$ Student of Agronomy Course, IFC Scholarship, IFC Campus Rio do sul, Brazil

${ }^{2}$ Student of the Technical Course in Agropecuaria, IFC Campus Rio do sul, Brazil

${ }^{3}$ Professor IFC, Advisor, PhD in Agronomy (Irrigation and Drainage), IFC Campus Rio do sul, Brazil

${ }^{4}$ Professor IFC, Co-Supervisor, PhD in Agronomy (Soil Science), IFC Campus Rio do sul, Brazil

${ }^{5}$ Professor IFG, Co-Supervisor, PhD in Agronomy (Vegetal Production), Ifgoiano Campus Iporá, Brazil

*Corresponding Author: Diogo Luiz Fruet, Student of Agronomy course, IFC Scholarship, IFC Campus Rio do Sul, Brazil.

Received: August 09, 2019; Published: September 20, 2019

DOI: 10.31080/ASAG.2019.03.0654

\section{Abstract}

In the Upper Vale of Itajaí, Beet is largely employed mainly in small farms as an alternative to income generation. It is believed that in many properties the irrigation occurs without the control of the water blade applied to the crop, directly affecting the cost, providing possible impairment with excesses or lack of water. In the region is widely used the use of rock dust, originating from slate with few researches carried out so far. The research conducted aimed to analyze the effect of different irrigation depths applied daily in the beet crop with doses of slate powder added to the soil. Twelve treatments were performed, being 3 daily irrigation slides, with 2 slides being calculated from the Hargreaves and Samdani equation and a $3 \mathrm{~mm}$ fixed blade with 4 doses of rock dust. The cultivation was carried out in the greenhouse of IFC Rio do Sul. The harvest was carried out 66 days after transplantation, and several morphological and qualitative data of the plants were evaluated. Analyzing the parameters it can be affirmed that the best irrigation blade was the corresponding to $130 \%$ of the crop evapotranspiration. In relation to rock dust, no significant correspondence was found for the development of the parameters considered.

Keywords: Water; Slate; Evapotranspiration

\section{Introduction}

In the upper Vale of Itajaí the culture is cultivated in small properties as an alternative to obtaining income. Beet cultivation has been growing in recent years and occupies an area of 773.1 ha, directly involving 296 families [1].

The use of water in agriculture far exceeds the other uses, so it becomes preponderant to employ a quantity of water close to the real need of the crop, to avoid losses and reduce costs. The uncontrolled use, most often occurs an excess, causing as secondary consequence the excessive use of manpower and energy, besides the favoring of diseases, reduction in growth and consequent reduction of quality and production. Concomitantly, the generalization of methods of determination of irrigation needs, which are generally generalists, makes necessary the regional verification of the real need for culture. The irrigation has impacted the beet crop in the region of Alto Vale do Itajaí, due to the increase of productivity and lower risk of production loss, besides the use of the structure that is already used in the onion.

Moreover, because it is low cost and available in the region of Alto Vale do Itajaí is being used rock dust (slate). Horticultures without technical criteria and without an orientation use varying amounts of rock dust, ranging from 3 to 10 tons. ha- 1 with the expectation of resulting in productive gains, which does not always occur and requires scientific proof.

The objective of this research was to verify the effect of the application of different irrigation depths and doses of silicatic rock powder (slate stone) on the development and productivity of the beet crop.

\section{Materials and Methods}

The experiment was carried out in a protected environment at the Instituto Federal Catarina's in Rio do Sul - SC with the beet cultivar boron. The cultivation was carried out from October to December 2017.

The soil used in the vessels was a Cambisssolo (clay $=240$ g.kg ${ }^{1}$ ) with the following chemical attributes: $\mathrm{PH}$ (water) $=6$; $\mathrm{P}$ and $\mathrm{K}$ $=5.3$ and 212 mg.DM ${ }^{-3}$ of them; $\mathrm{Ca}, \mathrm{Mg}$ and $\mathrm{Al}: 4.2 ; 1.2$ and 0 Cmolc. $\mathrm{DM}^{-3}$ of them , respectively; base saturation $(\mathrm{V})=67.2 \%$. Soil fertilization was performed using $\mathrm{N}, \mathrm{P}, \mathrm{K}$ and $\mathrm{S}$ fertilization, with a dose of $115,425.5,115$ and $30 \mathrm{~kg}$. ha ${ }^{-1}$ respectively, all the fertilizations were incorporated into the soil. The seedlings were produced in expanded polystyrene trays, transplanted 30 days after sowing, at 
28 days after transplantation (DAT) The thinning was performed. Weed control was performed manually, disease control was carried out with protective fungicide applications, insecticides were used for pest control.

The doses of rock dust applied in the vessel were adjusted by the arable layer 0-20 cm, with loose soil density of $1 \mathrm{~g} . \mathrm{cm}^{-3}$, using doses of $0,5,10$ and 15 ton. ha ${ }^{-1}$. The vessels were prepared in advance of the transplant, being kept moist for the reaction of the rock dust with the soil.

Irrigation was managed as follows, in the first days after transplantation with fixed slides for all treatments after this, to evaluate the efficiency of the water slide, the Hargreaves - Samdani equation was used, taking into account the Variables required by the same and the data that we would have available for collection, together with the irrigation blade that presented the best result during the experiment conducted by the same author in the period from may to June 2017, where the blade of Best result was $3 \mathrm{~mm}$ daily irrigation. The model proposed by Hargreaves and Samani [2] to estimate the evapotranspiration of ET o reference $\left(\mathrm{mm}\right.$. Day $\left.{ }^{-1}\right)$ is represented in the equation:

Reference evapotranspiration $=\mathrm{a} \operatorname{Ra} \mathrm{TD}^{1 / 2}(\mathrm{tmed}+17.8)$

Where

A: The dimensional coefficient, whose proposed value is 0.0023 .

Ra: Extraterrestrial solar radiation incident at the top of the atmosphere, MJ. M-2 Day ${ }^{-1}$

TD: Is the temperature variation in the day, (Tmax-Tmin) in ${ }^{\circ} \mathrm{C}$

Tmed: Daily average temperature $0.5(\mathrm{Tmax}+\mathrm{Tmin})$ in ${ }^{\circ} \mathrm{C}$

The extraterrestrial solar radiation was obtained through the climatic monitoring station of Tutoring, with the conversion of data, as the experiment was carried out in the greenhouse, the index is found in the literature that only $60 \%$ of the radiation value passes the film This value was used to perform the calculations. With the reference evapotranspiration values, we used the values of culture coefficient (Kc) proposed by Dorenbos and Pruitt, 1977, considering an interval of 22 days each coefficient starting with the second value due to the plants being Transplanted.

Thus, the irrigation treatments were: $\mathrm{T} 1=$ Blade calculated by the equation and $\mathrm{Kc}, \mathrm{T} 2=3 \mathrm{~mm}$ and $\mathrm{T} 3=130 \%$ of the blade calculated by the equation and Kc.

The harvest was performed at 60 DAT, and data were extracted from tuberous root mass, tuberous root diameter, total yield (estimated with a population of 300000 plants.ha $^{-1}$ ), chlorophyll, using the SPAD Index, with direct measurement of chlorophyll, fresh leaf mass, dry mass of the leaves and Brix with the use of the refractometer, with the appropriate measures to avoid errors in the readings.

It was used a completely randomized design (IHD) with 3 replications (blocks), with 12 treatments each, with a $3 \times 4$ factorial scheme, three water slides (Lamina calculated by the equation,
$3 \mathrm{~mm}$ and $130 \%$ of the lamina calculated by the equation) and four doses of powder Rock Stone Slate 0, 5, 10:15 tons. ha ${ }^{-1}$ numbered from 1 to 4 respectively, totaling 36 experimental plots. Each parcel corresponded to a vessel with a volumetric capacity of $8 \mathrm{~L}$. The data were subjected to the analysis of the ASSISTAT program, applying the Tukey test at a level of $1 \%$ and $5 \%$ of probability.

\section{Results and Discussions}

In the conduction period of the experiment, the averages of maximum and minimum temperatures were, respectively $28.05^{\circ} \mathrm{C}$ and $16.27^{\circ} \mathrm{c}$, and the average of the maximum and minimum humidifies were, respectively, $82.48 \%$ and $45.81 \%$. According to Figueira [3], Beet produces well in mild or low temperatures, with better development at temperature around $20^{\circ} \mathrm{c}$, and we do not recommend long periods with temperatures above $25^{\circ} \mathrm{C}$.

To obtain an overview of the data distribution behavior, descriptive statistical analysis was performed for all the variables studied.

According to the data shown in table 1, we can perceive the effect of irrigation slides on the variables analyzed, being treatment 3 which resulted in better Mis days, occurring difference, in the tuberous root mass, productivity, mass Fresh leaves and Brix, with no difference between treatment 1 and 3 in the tuberous root diameter and dry mass of leaves.

Chlorophyll content analysis revealed the lower development of plants subjected to treatment 1 and 2 concomitantly with no difference between treatments 2 and 3, and the smallest masthead recorded in Treatment 3. In the analysis of Brix to a higher concentration in treatment 3 , being favored by the best utilization of nutrients and its absorption by water.

The results demonstrate the low efficiency in the use of rock dust on the Misevaluated days, that is, an unnecessary cost, where even at the highest dose were not large differences in the productivity, being the treatment 2 with 5 ton.ha ${ }^{-1}$ What represented the best use of slate rock dust.

The differences found in the irrigation slides agree with several authors, in which according to Silva., et al. [4], such differences may be caused by the low tolerance of table beet to the water deficit, which leads this crop to increasing losses of Income. Sadeghian and Yavari [5] observed a reduction of the plants according to the decrease in potential when they studied the effect of water deficit on beet growth and germination.

The smallest mass of plants with lower irrigation depth agrees with Tivelli., et al. [6], which proposed how the water constitutes about $90.9 \%$ of the aerial part and $87.3 \%$ of the root of the beet crop, and the lack of water responsible for the drastic fall in the development and Production of this vegetable. The occurrence of water deficit in vegetables compromises the productivity and its quality because of its short cycle and high water content in its constitution. Therefore, any occurrence of stress can lead to low yield and losses in production [7]. 


\begin{tabular}{|c|c|c|c|c|c|c|c|}
\hline Factor & MRT (g) & DRT (mm) & PR (kg.has ${ }^{-1}$ ) & CL & MFF (g) & MSF (g) & B (\%) \\
\hline \multicolumn{8}{|l|}{ Irrigation (I) } \\
\hline $\mathrm{T} 1$ & $67,66 \mathrm{~b}$ & 48.41 from & $20300 \mathrm{~b}$ & 53,48 a & $41,50 \mathrm{~b}$ & 10.07 from & $6,55 \mathrm{~b}$ \\
\hline $\mathrm{T} 2$ & $63,50 \mathrm{~b}$ & $47,49 \mathrm{~b}$ & $19050 \mathrm{~b}$ & 48.72 from & $42,00 \mathrm{~b}$ & $8,90 \mathrm{~b}$ & $6,32 \mathrm{~b}$ \\
\hline T 3 & $95,66 \mathrm{a}$ & $53,79 \mathrm{a}$ & $28700 \mathrm{a}$ & $46,25 \mathrm{~b}$ & $53,00 \mathrm{a}$ & $11,79 \mathrm{a}$ & $8,08 \mathrm{a}$ \\
\hline \multicolumn{8}{|l|}{$\begin{array}{l}\text { Rock Powder } \\
\text { (R) }\end{array}$} \\
\hline $\mathrm{T} 1$ & $68,22 \mathrm{a}$ & $48,28 \mathrm{a}$ & $20466 \mathrm{a}$ & $46,78 \mathrm{a}$ & $47,11 \mathrm{a}$ & $8,31 \mathrm{a}$ & $6,43 \mathrm{a}$ \\
\hline T 2 & $82,22 \mathrm{a}$ & $51,64 \mathrm{a}$ & $24666 \mathrm{a}$ & $48,71 \mathrm{a}$ & $48,22 \mathrm{a}$ & $10,63 \mathrm{a}$ & $7,19 \mathrm{a}$ \\
\hline Т 3 & $74,44 \mathrm{a}$ & 49,60 a & $22333 \mathrm{a}$ & 50,75 a & $44,44 \mathrm{a}$ & $10,72 \mathrm{a}$ & $7,29 \mathrm{a}$ \\
\hline $\mathrm{T} 4$ & $77,55 \mathrm{a}$ & $50,08 \mathrm{a}$ & $23266 \mathrm{a}$ & 51,70 a & $42,22 \mathrm{a}$ & $11,35 \mathrm{a}$ & $7,02 \mathrm{a}$ \\
\hline I & $11,69^{* *}$ & $4,66^{*}$ & $11,69^{* *}$ & $6,41^{* *}$ & $5,78^{* *}$ & $4,89^{*}$ & $9,19^{* *}$ \\
\hline $\mathrm{R}$ & $0,98^{\mathrm{NS}}$ & $0,58^{\mathrm{NS}}$ & 0,98 Ns & $1,70^{\mathrm{NS}}$ & 0,74 NS & 3,04 NS & $1,10^{\mathrm{NS}}$ \\
\hline IxR & 0,82 NS & $0,55^{\mathrm{NS}}$ & 0,82 NS & $0,57^{\mathrm{NS}}$ & $0,55^{\mathrm{NS}}$ & $1,30 \mathrm{NS}$ & 0,49 Ns \\
\hline C.V. (\%) & 23,43 & 10,95 & 13,7 & 10,17 & 20,58 & 22,40 & 15,62 \\
\hline
\end{tabular}

Table 1: Synthesis of the values of analysis of variance and test of averages for the variables tuberous root mass (MRT), tuberous root diameter (DRT), yield (PR), chlorophyll (CL), fresh mass of Leaves (MFF), dry mass leaves (MSF) and Brix (B). Ns: Non-significant $(\mathrm{P}>0.05) ;{ }^{*}$ : Significant $(\mathrm{P}<0.05) ;{ }^{* *}$ : Significant $(\mathrm{P}<0.01)$; C.V.: Coefficient of variation.

These results are similar to those found by Oliveira Neto., et $a l$. [8], evaluating the Early Wonder cultivar in different irrigation depths and soil cover in organic cultivation. In this study, the authors found an average of $55 \mathrm{~mm}$ in diameter of the tuberous root, slightly above that found by this work, and the difference may be caused by the cultivation in pots, affecting the diameter of the tuberous root.

The results found for rock dust differ from Santos, Silva and beserra [9], verified a positive effect of rock dust on potato production, but with a tendency to decrease, and affirmed that the best yields were in the doses of 3.18 ton. ha-1.

\section{Conclusion}

The irrigation blade with the best performance and productivity was the use of $130 \%$ of the crop evapotranspiration, and the significant difference in the use of slate rock dust was not found.

\section{Bibliography}

1. Oliveira R Jp., et al. "Calibration of phosphate and potassic fertilization for beet in the Vale do Itajaí region". Brazilian Horticulture 34 (2016): 210-215.

2. Borges AC and Mendiondo EM. “Comparison between empirical equations for estimation of reference evapotranspiration in the Jacupiranga River basin". Brazilian Journal of Agricultural and Environmental engineering, Campina Grande 11.3 (2007): 293-300.

3. Filgueira FAR. "New Manual of Olericulture: Modern Agrotechnology in the production and commercialization of vegetables". Federal University of Viçosa. MG: UFV (2006): 357.
4. Silva., et al. "Water use efficiency in beet cultivars subjected to different water tensions in the soil". Water Resources and Irrigation Management, Campina Grande 2.1 (2013): 27-36.

5. Sadeghian SY and Yavari N. "Effect of Water-Deficit Stress on Germination and Early Seedling Growth in Sugar Beet". Journal of Agronomy and Crop Science 190.2 (2004): 138-144.

6. Tivelli SW., et al. "BAeet from planting to commercialization". 210. edition. Campinas: Instituto Agronômico, IAC Technical Bulletin (2011): 45.

7. Silva 0., et al. "Development of beet cultivars under different water tensions in the soil". Horticulture Brasilia 33.1 (2015): 012-018.

8. Oliveira Neto DH. "Water need, response function and quality of beet (Beta vulgaris L.)". under different irrigation depths and soil covers in organic cultivation system 120 (2009).

9. Santos JF., et al. "Agroecological production of potatoes in relation to doses of rock dust". (2014).

Volume 3 Issue 10 October 2019 (C) All rights are reserved by Diogo Luiz Fruet., et al. 